\title{
Geometrical features of micro milling cutters for machining of medical components made of titanium alloys
}

\author{
Alexander Isaev ${ }^{1, *}$, Ramil Khamzin ${ }^{1}$, Ilya Minin ${ }^{1}$, Petr Pivkin ${ }^{1}$, and Marco Leonesio ${ }^{2}$ \\ ${ }^{1}$ Moscow State University of Technology "STANKIN", 127055 Moscow Vadkovskiy lane 1, Russia \\ ${ }^{2}$ Institute of Intelligent Industrial Technologies and Systems for Advanced Manufacturing of the \\ National Research Council, STIIMA-CNR, 20133 Via Alfonso Corti 12, Milano, Italy
}

\begin{abstract}
Micromachining is an increasingly important material cutting process which is performed on workpieces in micro-scale. It is widely used in rapidly developing advanced areas like electronic, aerospace and medical industries. In medical industry, micromachining is applied for producing instruments, joint implants and dentures. The medical components should be made only of biologically compatible and hard-tomachine materials such as cobalt and nickel based alloys, ceramics and titanium alloys. For manufacturing medical components, small-sized end mills with working diameter of less than $1 \mathrm{~mm}$ are often used. Such micro milling cutters impose difficulties on the mechanical micromachining process. To determine the functional relationships between structural strength, cutting properties and geometry of a micro milling cutter, a mathematical model is derived in this paper. Before experimental phase, the calculation of cutting forces was performed as this will reduce the time to determine the optimal cutting data and maximize the tool life.
\end{abstract}

\section{Introduction}

The use of micro cutting tools allows producing complex-shaped parts with high quality meeting the strict requirements for medical parts (Fig.1-4). However, the efficiency and effectiveness of micromachining depends on many variables including workpiece material properties, cutting tool parameters [1-8], process parameters, machine tool characteristics and many others.

It is well known that titanium and its alloys are the most biologically compatible of all metals due to their high corrosion resistance, strength and low modulus [2-5]. At the same time, the physical and mechanical properties of titanium alloys (Table 1) cause certain difficulties in their machining, namely:

- relatively low modulus of elasticity produces vibrations during cutting;

- low ductility causes negative chip shrinkage;

\footnotetext{
* Corresponding author: avisz@yandex.ru
} 
- low thermal conductivity and high heat resistance intensively generate heat which upsets the heat balance during machining with heat transfer through cutting tool resulting in increased tool wear [1-4];

- chemical interaction with gases at elevated temperatures induced during cutting increases the hardness of workpiece superficial layer [2, 3, 4, 7].

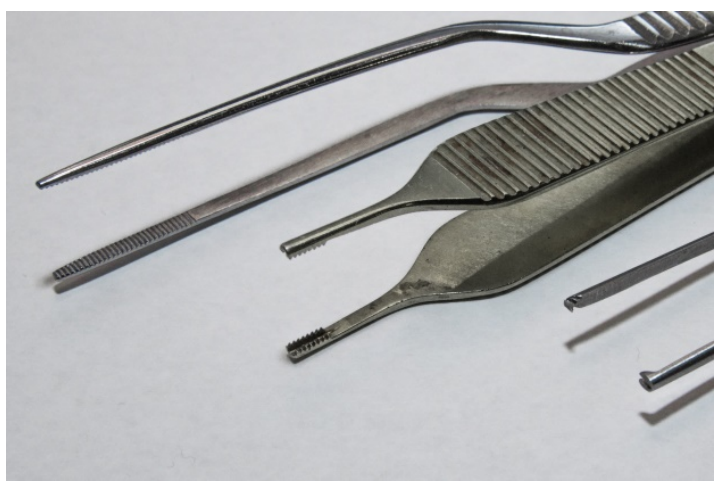

Fig. 1. Medical tweezers made of TiAl6V4 having jaws machined with end mill Ø1.0 mm.

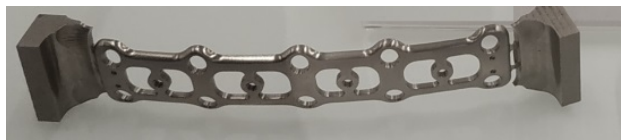

Fig. 2. Cervical spine plate made of TiAl6V4 machined with end mill Ø0.3 mm.

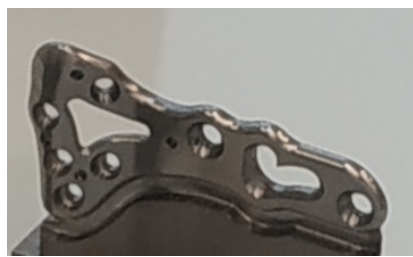

Fig. 3. Plate to the radial bone from TiAl6V4 machined with end mill $\varnothing 0.3 \mathrm{~mm}$.

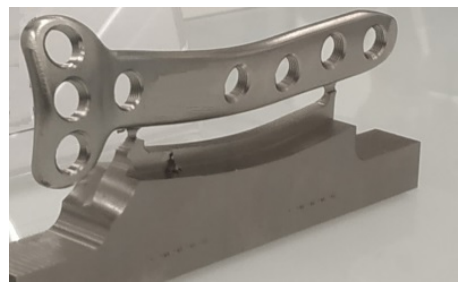

Fig. 4. Plate for osteosynthesis from TiAl6V4 machined with end mill Ø1.0 mm.

Table 1. Mechanical properties of titanium alloy TiAl6V4.

\begin{tabular}{|c|c|c|c|c|}
\hline Grade class & $\begin{array}{c}\text { Specific } \\
\text { cutting force } \\
\text { per } 1 \mathbf{~ m m}^{2} \text { of } \\
\text { chip section } \\
\mathrm{K}_{\mathrm{cl} 1.1} \\
\mathrm{~N} / \mathbf{m m}^{2} \\
\end{array}$ & $\begin{array}{c}\text { Tensile } \\
\text { strength, } \\
\text { MPa }\end{array}$ & $\begin{array}{c}\text { Heat } \\
\text { treatment } \\
\text { type }\end{array}$ & $\begin{array}{c}\text { Hardness, } \\
\text { HRC }\end{array}$ \\
\hline$\alpha+\beta$ grade & 1370 & $850-1200$ & $\begin{array}{l}\text { precipitation } \\
\text { hardening }\end{array}$ & $39-41$ \\
\hline
\end{tabular}




\section{Methods}

\subsection{Influence of rounding radius of the cutting edge on cutting data parameters}

The efficiency of chip formation during milling is largely determined by the ratios $f_{\mathrm{z}} / \rho$ and $a_{\mathrm{e}} / \rho$, where $f_{\mathrm{z}}$ is the feed per tooth, $a_{\mathrm{e}}$ is the width of cut, $\rho$ is the cutting edge rounding radius (Fig.5). These conditions are especially important when machining with small-sized milling cutters. When feed per tooth and cutting depth are lower than the rounding radius, i. e. $f_{\mathrm{z}}<\rho$ and $a_{\mathrm{e}}<\rho$, the cutting capacity of the milling tooth get worse. In this case, the actual rake angle becomes negative, consequently instead of cutting the intensive wear of workpiece material is observed leading to the increase of cutting forces. The compression deformations in the contact layer of the workpiece material produce wear hardening [5]. This worsens the cutting conditions for the following cutting tooth. The same effects present in up-milling where at the tooth entrance the thickness of the cut layer is zero.

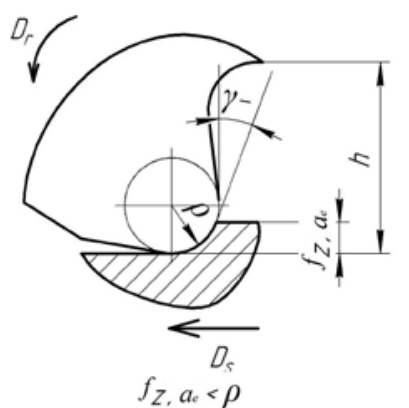

a)

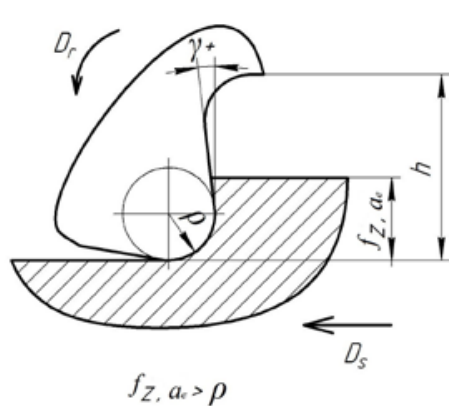

b)

Fig. 5. Cutting edge rounding radius related to the cutting data parameters: a) conditions for inefficient chip formation, b) conditions for effective chip formation.

During manufacturing of the cutting tool, the value of $\rho$ is affected by the parameters as follows:

- cutting material grade and its grain and pore size[11];

- wear resistant coating deposition parameters[2-10].process parameters, i. e. grinding wheel parameters, grinding speed, feed rate and cutting depth[11];

- roughness of rake and flank surfaces[11-12];

- wear resistant coating deposition parameters[2-10].

- process parameters, i. e. grinding wheel parameters, grinding speed, feed rate and cutting depth[11-15];

To determine the minimum allowable values of the process parameters required for stable chip formation, the geometry of a micro milling cutter of the GF500T series manufactured by Guhring was analyzed (Fig. 6). According to the manufacturer's catalog, the end mill has the following geometric parameters: outer diameter $d=0.5 \mathrm{~mm}$, helical angle $\omega=30^{\circ}$, peripheral rake angle $\gamma=8^{\circ}$, and the corner radius $R=0.01 \mathrm{~mm}$. The recommended cutting data for processing titanium alloys are: feed per tooth $f_{\mathrm{z}}=0.007$ $\mathrm{mm} /$ tooth, width of cut $a_{\mathrm{e}}=0.1 \mathrm{~mm}$, axial depth of cut $a_{\mathrm{p}}=0.05 \mathrm{~mm}$. 


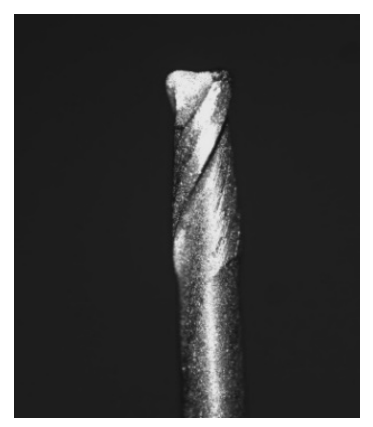

Fig. 6. GF500T micro end mill with $d=0.5 \mathrm{~mm}$ by Guhring displayed at GFM MikroCAD premium + measuring machine in enlarged view.

The general geometrical parameters of the micro end mill were measured using measuring machine Walter Helicheck Plus (Fig. 7 and Table 2). The cutting edge rounding radii were measured with GFM MikroCAD premium+ Microscope (Fig. 8 and Table 3). It was found that the rake angle measured at a distance of $0.6 \mathrm{~mm}$ from the tool top is negative and is equal to approx. $-8^{\circ}$ (Fig. 9). The cutting edge rounding radius is irregular and takes values in the range of $7 \ldots 9 \mu \mathrm{m}$ in different cross-sections normal to the helical cutting edge (Fig.10).

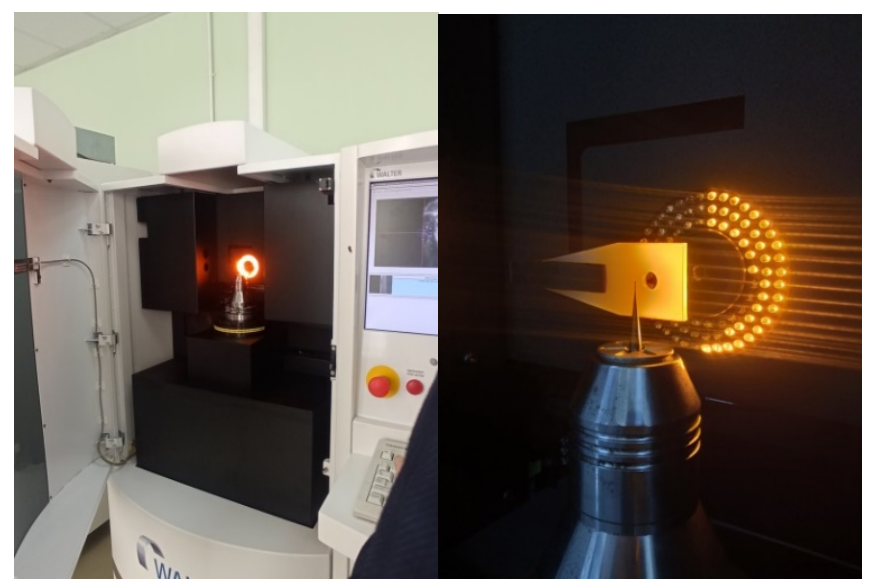

Fig. 7. Measurement the geometry of GF500T micro end mill with $d=0,5$ by Guhring using Walter Helicheck Plus measuring machine.

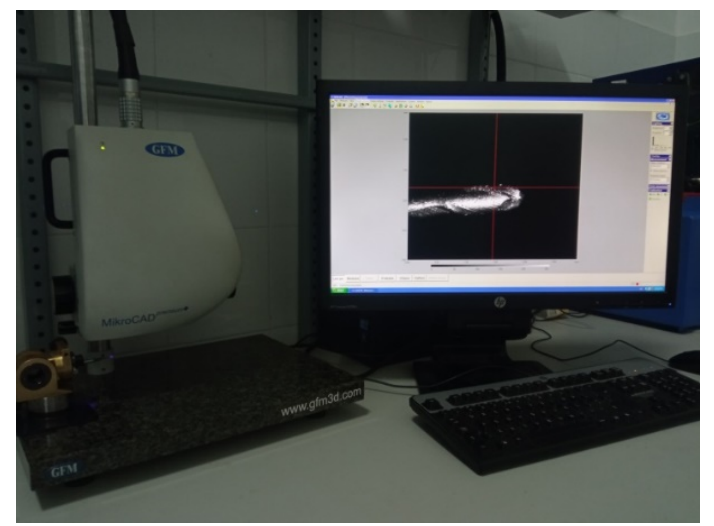

Fig. 8. Measurement the cutting edge rounding radius using GFM MikroCAD premium+ Microscope. 
Table 2. Accuracy and magnification data of Walter Helicheck Plus.

\begin{tabular}{|c|c|}
\hline Parameter & Value \\
\hline Repetition accuracy & $\leq 1 \mu \mathrm{m}$ \\
\hline $\begin{array}{c}\text { Position resolution for all linear } \\
\text { axes X, Y, Z }\end{array}$ & $0,004 \mu \mathrm{m}$ \\
\hline $\begin{array}{c}\text { Position resolution for rotation } \\
\text { axis A }\end{array}$ & $<0.00036^{\circ}$ \\
\hline Measurement value resolution & $0,25 \mu \mathrm{m}$ \\
\hline Back light camera 1 & $50 \mathrm{x}$ \\
\hline Back light camera 2 & $400 \mathrm{x}$ \\
\hline Front light camera & $400 \mathrm{x}$ \\
\hline op light camera & $400 \mathrm{x}$ \\
\hline
\end{tabular}

Table 3. GFM MikroCAD premium+ Microscope technical data.

\begin{tabular}{|c|c|}
\hline Parameter & Value \\
\hline Resolution $X$ & $0.7 \mu \mathrm{m}$ \\
\hline Resolution $Z$ & $0,07 \mu \mathrm{m}$ \\
\hline Field of View & $1,7 \times 1,4 \mathrm{~mm}$ \\
\hline Measurement Range & $0,5 \mathrm{~mm}$ \\
\hline
\end{tabular}

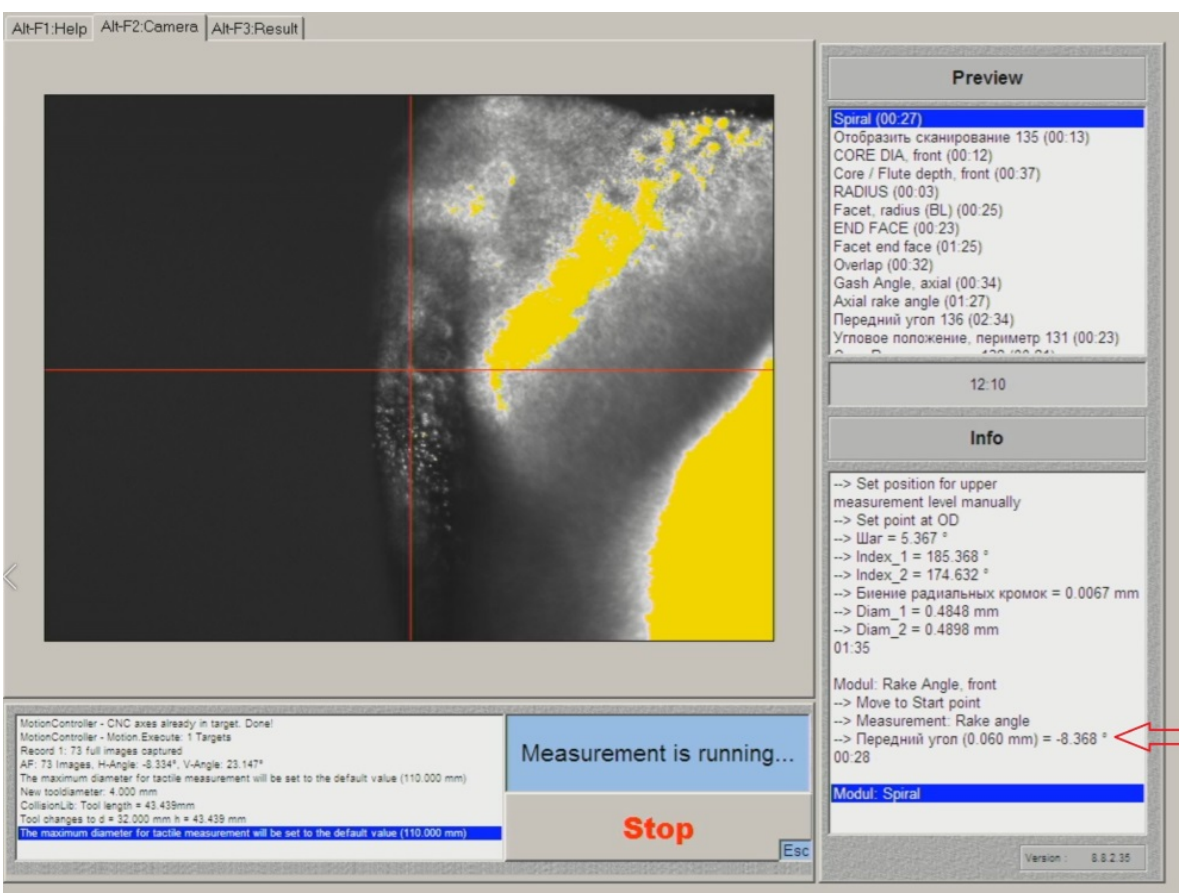

Fig. 9. Window of Walter Helicheck Plus measuring software showing the value of rake angle of GF500T micro end mill by Guhring. 

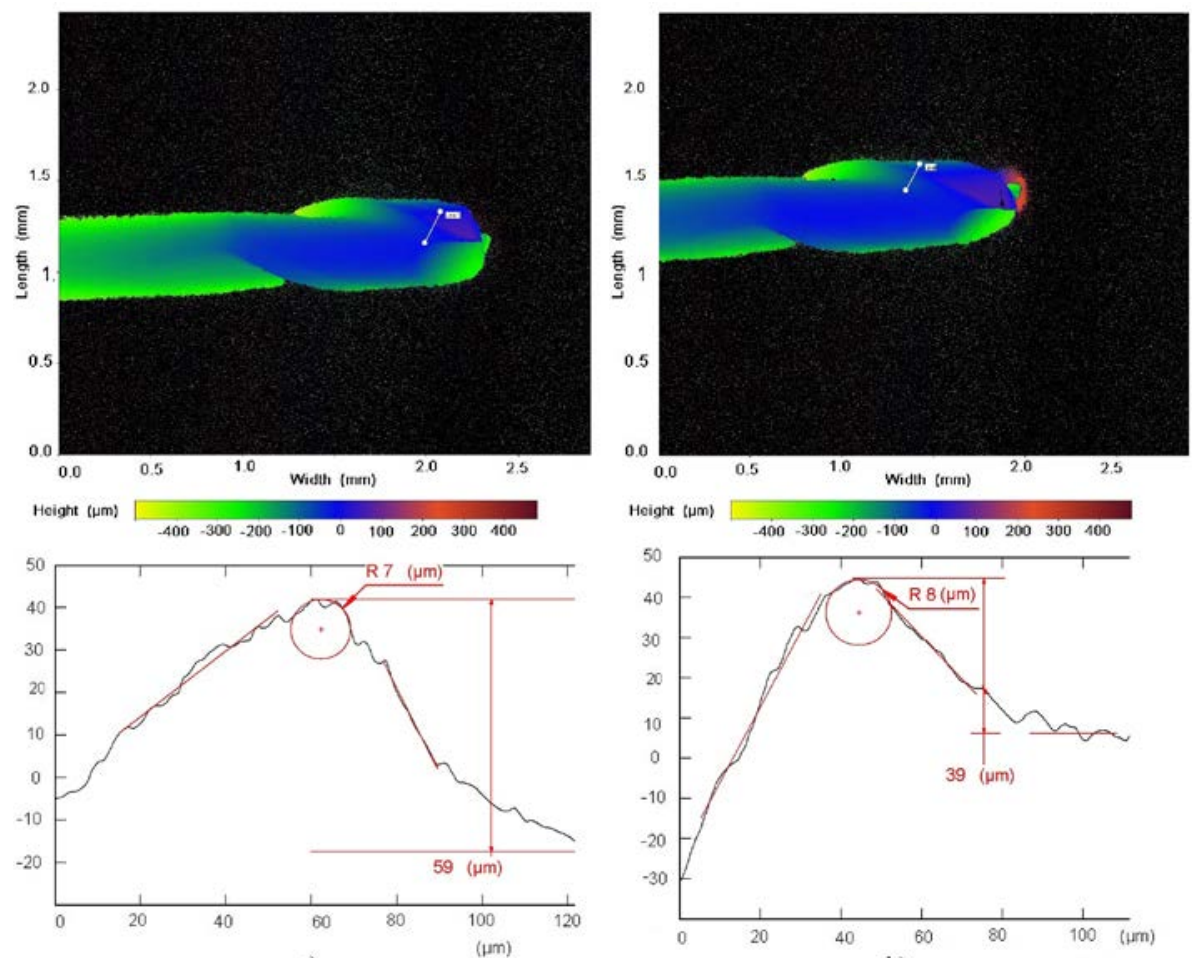

a)

b)
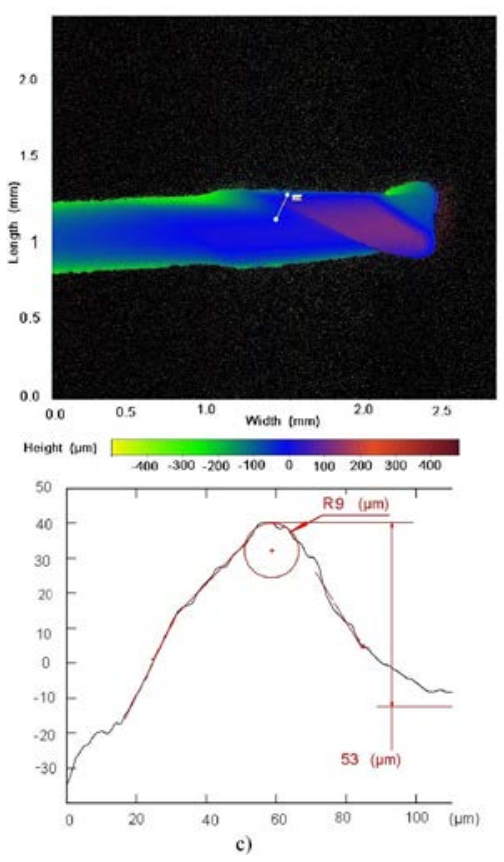

Fig. 10. Cutter's surface topography and cross sections showing cutting edge rounding radius of GF500T micro end mill by Guhring at GFM MikroCAD premium+ Microscope: a) at a length of 0.3 $\mathrm{mm}$ from the top, b) at a length of $0.5 \mathrm{~mm}$ the top, c) at a length of $0.8 \mathrm{~mm}$ from the top. 


\subsection{Mathematic models for calculating a cutting speed angles and working kinematic clearance angles for down and up milling}

During the cutting, both the angle of cutting speed $\eta$ and the working kinematic clearance angle $\alpha_{p}$ measured between the flank surface and the direction of the resultant cutting speed change. The behavior of the angle $\eta$ is affected by the milling direction. When down milling, at the point of engagement into the material, the angle $\eta$ has the maximum value and gradually decreases with moving to the the point of disengagement, increasing the value of the angle $\alpha_{p}$. In up-milling, the angle $\eta$ gradually increases as the cutter engages into the material thereby reducing the working clearance angle $\alpha_{\mathrm{p}}$ (Fig.11).

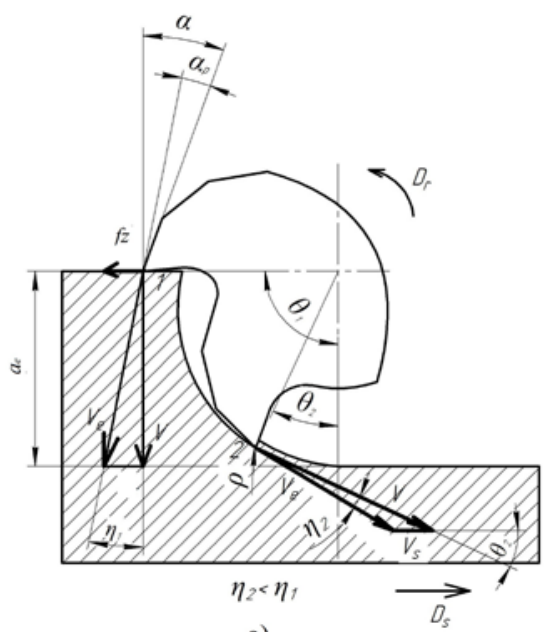

a)

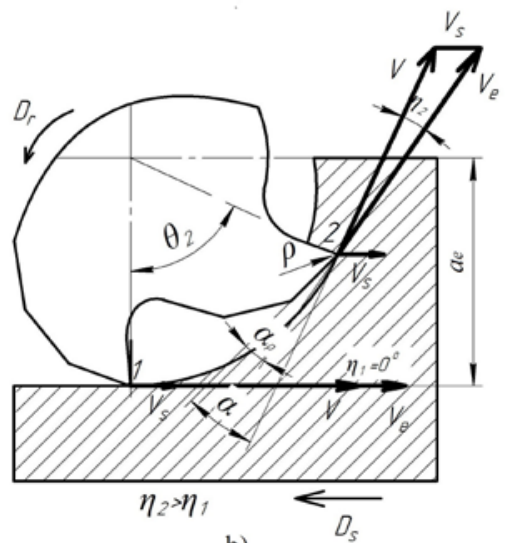

b)

Fig. 11. Change of the angle $\eta \mathrm{n}$ the working plane at different moments of the working stroke of the mill: a - in down-milling, $\eta_{2}<\eta_{1}, b-$ in up-milling, $\eta_{2}>\eta_{1} ; 1-$ the point at the moment when the cutting edge engages into the workpiece, 2 - the point engaged into the workpiece; $V$ - the velocity of the main cutting movement at the considered cutting point; $V_{\mathrm{e}}-$ the velocity of the resulting cutting speed; $V_{\mathrm{s}}$ - the velocity of the feed; $\eta$ - the cutting speed angle; $\theta_{1}, \theta_{2}$ - the angles of contact of cutting tooth with the workpiece surface at the engagement and at some instance, respectively; $a_{\mathrm{e}}-$ the radial depth of cut; $\alpha_{p}$ - the kinematic clearance angle in the working plane; $\alpha$ - the clearance angle, $\rho$ - the cutting edge rounding radius.

With the decrease in the angle $\alpha_{\mathrm{p}}$, a greater amount of heat is absorbed by cutter thus reducing the tool life and deteriorating the surface quality due to decreasing clearance between the flank and the workpiece surfaces, especially when machining using micro end mills.

To create mathematical models for calculating the $\alpha_{\mathrm{p}}$ angle basing on the cutting data, the schemes of milling process in the working plane (Fig. 12) are used. The kinematic clearance angle is equal to:

$$
\alpha_{\mathrm{p}}=\alpha-\eta
$$




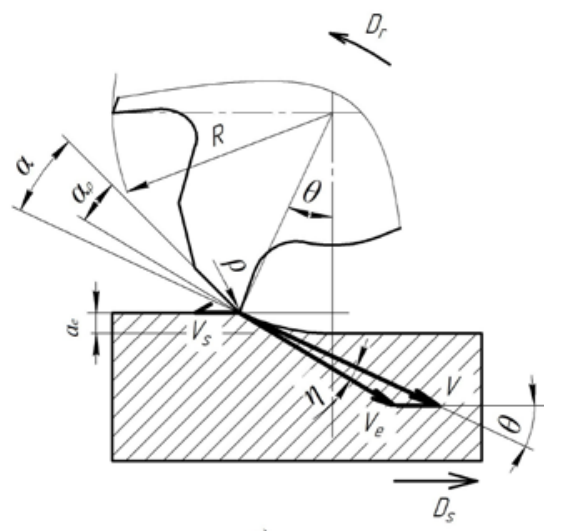

a)

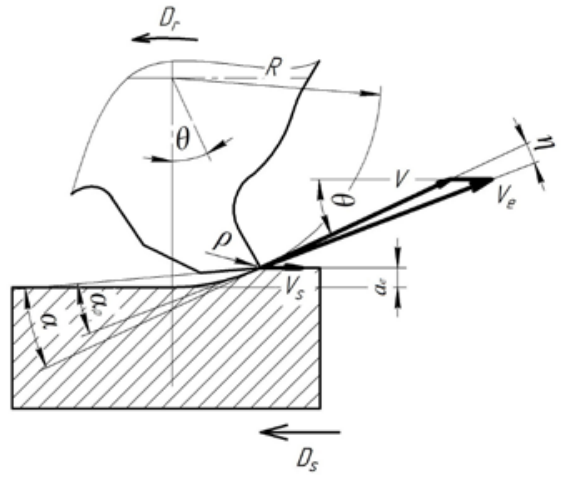

b)

Fig. 12. Schemes of milling for determination the angles $\eta$ and $\alpha_{p}, a$ - in down milling, $b$ - in upmilling, $V$ - the velocity of the main cutting movement at the considered cutting point; $V_{\mathrm{e}}-$ the velocity of the resulting cutting speed; $V_{\mathrm{S}}$ - the velocity of the feed; $\eta$ - the cutting speed angle; $\theta_{1}$, $\theta_{2}$ - the angles of contact of cutting tooth with the workpiece surface at the engagement and at some instance, respectively; $a_{\mathrm{e}}$ - the radial depth of cut; $\alpha_{\mathrm{p}}$ - the kinematic clearance angle in the working plane; $\alpha$ - the clearance angle, $\rho$ - the cutting edge rounding radius, $D_{\mathrm{s}}$ - the feed velocity, $D_{\mathrm{r}}-$ the main cutting movement velocity.

To determine the speed of the resulting velocity $\mathbf{V}_{\mathbf{e}}$ we should first calculate the cutting speed as follows:

The feed rate is equal to:

The contact angle $\theta$ is defined as:

$$
\boldsymbol{V}=2 \pi R
$$

$$
\mathbf{V}_{\mathbf{s}}=f_{\mathrm{z}}
$$

$$
\cos \theta=1-\frac{t}{R}
$$

According to the diagram in Fig. 12, we can express the resulting cutting speed

- for down-milling:

$$
\boldsymbol{V}_{\boldsymbol{e}}^{2}=\mathbf{V}^{2}+\mathbf{V}_{\mathrm{s}}^{2}-\mathbf{2} \boldsymbol{V} \boldsymbol{V}_{\boldsymbol{s}} \cos \theta
$$

- for up-milling:

$$
\mathbf{V}_{\mathbf{e}}^{2}=\mathbf{V}^{2}+\mathbf{V}_{\mathbf{s}}^{2}-2 \mathbf{V V}_{\mathbf{s}} \cos (180-\theta)
$$

- for up- and down-milling:

$$
\mathbf{V}_{\mathbf{s}}^{2}=\mathbf{V}^{2}+\mathbf{V}_{e}^{2}-2 \mathbf{V} \mathbf{V}_{\mathbf{e}} \cos \eta
$$

Taking into account (2), (3) and (4), the equations (5-7) take the form:

$$
\begin{aligned}
\mathbf{V}_{\mathbf{e}}^{2} & =(2 \pi R)^{2}+f_{z}^{2}-4 \pi R S_{z}\left(1-\frac{a_{e}}{R}\right) \\
\mathbf{V}_{\mathbf{e}}^{2} & =(2 \pi R)^{2}+f_{z}^{2}-4 \pi R S_{z}\left(\frac{a_{e}}{R}-1\right) \\
f_{z}{ }^{2} & =(2 \pi R)^{2}+V_{e}^{2}-4 \pi R V_{e} \cos \eta
\end{aligned}
$$

From equation (10) we obtain:

$$
\cos \eta=\frac{(2 \pi R)^{2}+\mathbf{V}_{\mathbf{e}}^{2}-f_{\mathbf{Z}}^{2}}{4 \pi R \mathbf{V}_{\mathbf{e}}}
$$


Substituting equations (8) and (9) into equation (11) and simplifying it, we obtain the mathematical models for calculating:

- the angle of the cutting speed during down-milling:

$$
\eta=\arccos \left(\frac{2 \pi R^{2}-f_{Z} R+f_{Z} a_{e}}{R \sqrt{\left(2 \pi R-f_{\mathrm{Z}}\right)^{2}+4 \pi f_{\mathrm{Z}} a_{e}}}\right)
$$

- the angle of the cutting speed during up-milling:

$$
\eta=\arccos \left(\frac{2 \pi R^{2}-f_{z} a_{e}+f_{Z} R}{R \sqrt{\left(2 \pi R+f_{z}\right)^{2}-4 \pi f_{z} a_{e}}}\right)
$$

Taking into account the expression (1), we obtain the mathematical models for calculating the $\alpha_{\mathrm{p}}$ angle

- for down-milling:

$$
\alpha_{\mathrm{p}}=\alpha-\arccos \left(\frac{2 \pi R^{2}-f_{z} R+f_{z} a_{e}}{R \sqrt{\left(2 \pi R-S_{z}\right)^{2}+4 \pi f_{\mathrm{z}} a_{e}}}\right)
$$

- for up-milling:

$$
\alpha_{\mathrm{p}}=\alpha-\arccos \left(\frac{2 \pi R^{2}-f_{z} a_{e}+f_{z} R}{R \sqrt{\left(2 \pi R+f_{z}\right)^{2}-4 \pi f_{z} a_{e}}}\right)
$$

The obtained mathematical models allow us to determine in the working plane the dependence of the $\alpha_{\mathrm{p}}$ angle on the milling width $a_{\mathrm{e}}$ and the feed $f_{\mathrm{z}}$ for end mills of different diameters. The mathematical models determine the maximum value of the $\alpha_{\mathrm{p}}$ angle: for down-milling at the engagement of the milling tooth into the workpiece, and for up-milling at the disengagement of the milling tooth from the workpiece.

For micro milling cutters with helical teeth, the geometric parameters in the working plane relate to the geometric parameters in the normal cutting plane as follows:

$$
\tan \propto_{n}=\frac{\tan \propto_{p}}{\cos \omega}
$$

where $\propto_{n}$ is the clearance angle in the normal secant plane to the main cutting edge, $\propto_{p}$ is the clearance angle in the working plane, $\omega$ is the helix angle.

Therefore, $\propto_{\mathrm{n}}<\propto_{\mathrm{p}}$.

\subsection{Calculating cutting force for micro milling a part made of titanium alloy}

To perform a preliminary cutting force calculation, we use the input data recommended by Guhring, i. e. feed per tooth $f_{\mathrm{z}}=0.007 \mathrm{~mm}$, width of cut $a_{\mathrm{e}}=0.1 \mathrm{~mm}$, axial depth of cut $a_{\mathrm{p}}=0.05 \mathrm{~mm}$.

We used the Kienzle equation which is quite simple and gives adequate accuracy for many cutting applications. The basic Kienzle equation is as follows:

$$
F_{c}=k_{c} A,
$$

where $k_{c}$ is the specific cutting force depending on many variables including the properties of the tool/workpiece material pair, cutting part geometry and process parameters; $A$ is the cross section of the cut. The specific cutting force $k_{c}$ can be expressed as

$$
k_{c}=\frac{k_{c 1.1}}{h^{m}}
$$

where $k_{c l . l}$ and $m$ are material-dependent constants and $h$ is the thickness of the cut layer. For titanium alloy TiAl6V4: 


$$
\begin{gathered}
k_{c 1.1}=1370 \mathrm{~N} / \mathrm{mm}^{2} \\
m=0,21
\end{gathered}
$$

For milling operations, the $h$ is usually related to average undeformed chip thickness. The approximate equation for this parameter is:

$$
h=\frac{360^{\circ} a_{e}}{\pi \theta d} f_{z} \sin \varphi
$$

where $\theta$ is the contact arc angle, $a_{e}$ is the width of cut, $d$ is the cutter diameter, $f_{z}$ is the feed per tooth and $\varphi$ is the lead angle

$$
\begin{gathered}
h=\frac{360^{\circ} \cdot 0,1}{3,14159 \cdot 53,18 \cdot 0,5} \cdot 0,007 \cdot \sin \left(90^{\circ}\right) \\
h=0,00302 \mathrm{~mm}^{2} .
\end{gathered}
$$

Therefore:

$$
\begin{aligned}
k_{c} & =\frac{1370}{0,00302^{0,21}} \\
k_{c} & =4633 \mathrm{~N} / \mathrm{mm}^{2}
\end{aligned}
$$

The cross section of the cut $\mathrm{A}$ is generally a product of nominal cut thickness and the axial depth of cut. Finally:

$$
\begin{gathered}
F_{c}=k_{c} h a_{p} \\
F_{c}=4633,4 \cdot 0.00302 \cdot 0,05 \\
F_{c}=0,699 \mathrm{~N} .
\end{gathered}
$$

\section{Results and discussion}

The created mathematical models allow designing micro end mills with the geometrical parameters optimal in strength and determining the range of optimal feed values and width of cut $a_{\mathrm{e}}$ which must meet the conditions $\rho<f_{\mathrm{z}}<h$ and $\rho<a_{\mathrm{e}}<h$.

According to the measurement protocol, the cutting edge radius is irregular along the helical cutting edge having the values in the range of $7 \ldots 9 \mu \mathrm{m}$. For small-sized milling cutters, the cutting edge radius variation of $25 \%$ is very significant since at the recommended feed per tooth $f_{\mathrm{z}}=0.007 \mathrm{~mm}$ the chip formation is inefficient in all crosssections.

The actual measured value of the rake angle on the peripheral part of helical cutting edge turned out to be negative instead of the positive value showed in the catalog. This may result in significant variability in cutting process parameters when milling. At the same time, the negative geometry is a feasible solution for micro milling cutters made of advanced materials like reinforced cutting ceramics. These kinds of cutting tools may be suitable for use in machining medical components made of nickel and cobalt alloys because the negative design makes the cutting edge stiffer and stronger.

\section{Conclusions}

The derived mathematical models allow designing micro end mills with the geometry optimal in strength. These mathematical models can be exploited to determine the reasonable range of optimal cutting data for micro milling process. 
The negative values of rake angle acquired from measuring machine do not correspond with the catalog of the micro milling cutter manufacturer. Alternatively, the negative cutting geometry can be feasibly used for micro end mills made of cutting ceramics because this design feature makes the cutting edge stiffer and stronger.

To achieve high efficiency micro milling of construction materials, it is recommended to apply down-milling cutting strategy.

This work was supported by the Russian Science Foundation under grant 18-19-00599.

\section{References}

1. Kuzin, V.V., Grigoriev, S.N., Fedorov, M.Yu.,Role of the thermal factor in the wear mechanism of ceramic tools. Part 2: Microlevel, J. Frict. Wear. 36(1), 40-44 (2015)

2. Volosova, M.A., Grigor'ev, S.N. \& Kuzin, V.V,Effect of Titanium Nitride Coating on Stress Structural Inhomogeneity in Oxide-Carbide Ceramic, Part 4. Action of Heat Flow. Refract Ind Ceram 56, 91-96 (2015)

3. Vereschaka, Alexey A.; Grigoriev, Sergey N.; Sitnikov, Nikolay N. Batako, Andre, Working efficiency of cutting tools with multilayer nano-structured Ti-TiCN-(Ti,Al)CN and Ti-TiCN-(Ti,Al,Cr)CN coatings: Analysis of cutting properties, wear mechanism and diffusion processes, Surface and Coatings Technology, Volume 332, 2017, Pages 198-213

4. Kuzin, V.V., Grigor'ev, S.N., Volosova, M.A, Effect of a TiC Coating on the StressStrain State of a Plate of a High-Density Nitride Ceramic Under Nonsteady Thermoelastic Conditions, Refract. Ind. Ceram. 54, 376-380 (2014)

5. Grigoriev, S.N., Sobol, O.V., Beresnev, V.M., Serdyuk, I.V., Pogrebnyak, A.D., Kolesnikov, D.A., Nemchenko, U.S. Tribological characteristics of (TiZrHfVNbTa)N coatings applied using the vacuum arc deposition method. J. Frict. Wear 2014 35(5) 359-364

6. Metel, A.S., Grigoriev, S.N., Melnik, Yu.A., Bolbukov, V.P, Broad beam sources of fast molecules with segmented cold cathodes and emissive grids. Instrum. Exp. Tech. 2012 55(1) 122-130

7. A. Metel, V. Bolbukov, M. Volosova, S. Grigoriev, Yu. Melnik. Equipment for deposition of thin metallic films bombarded by fast argon atoms, Instruments and Experimental Techniques. Volume 57(3), pages 345-351 (2014)

8. Sobol', O. V., Andreev, A. A. Grigoriev, S. N., Stolbovoy, V. A, Physical characteristics, structure and stress state of vacuum-arc tin coating, deposition on the substrate when applying high-voltage pulse during the deposition. Problems of Atomic Science and Technology. №4, 2011. Pages. 174-177

9. Metel, A., Bolbukov, V., Volosova, M., Grigoriev, S., Melnik, Y. Source of metal atoms and fast gas molecules for coating deposition on complex shaped dielectric products. Surf. Coat. Technol 2013225 34-39

10. S. Grigoriev, Y. Melnik, A. Metel, Broad fast neutral molecule beam sources for industrial scale beam-assisted deposition. Surf. Coat. Technol. 156(1-3) (2002) 44-49.

11. Vladimir Grechishnikov, Sergey Grigoriev, Petr Pivkin, Marina Volosova, Alexander Isaev, Dmitry Nikitin and Ilya Minin, Design of Toroid-Shaped Solid Ceramic End Mill. EPJ Web of Conferences 224, 05001 (2019)

12. Xiangjing Kong, Zishan Ding, Lijun Xu, Lijian Zhu, Jian Zhang, Chongjun Wu and Alexander Isaev, Effects of Milling Parameters on Distribution of Residual Stress 
During the Milling of Curved Thin-Walled Parts, EPJ Web of Conferences 224, 05009 (2019)

13. I. A. Kovalev, P. A. Nikishechkin and A. S. Grigoriev. Approach to programmable controller building by its main modules synthesizing based on requirements specification for industrial automation. In: 2017 International Conference on Industrial Engineering, Applications and Manufacturing (ICIEAM), St. Petersburg, pp.1-4 (2017)

14. I.A. Kovalev, M.S. Babin, P.A. Nikishechkin. Development of a method for the determination and registration of unauthorized data transmission channels at industrial manufactories, MATEC Web of Conferences, Vol. 298, p. 00110. EDP Sciences (2019)

15. P.A. Nikishechkin, N.S. Grigoriev, N.Yu. Chervonnova. Construction of a specialized control system for brush machine and rounding the cutting edges of a metal cutting tool, MATEC Web of Conferences, Vol. 298, p. 00064. EDP Sciences. (2019) 